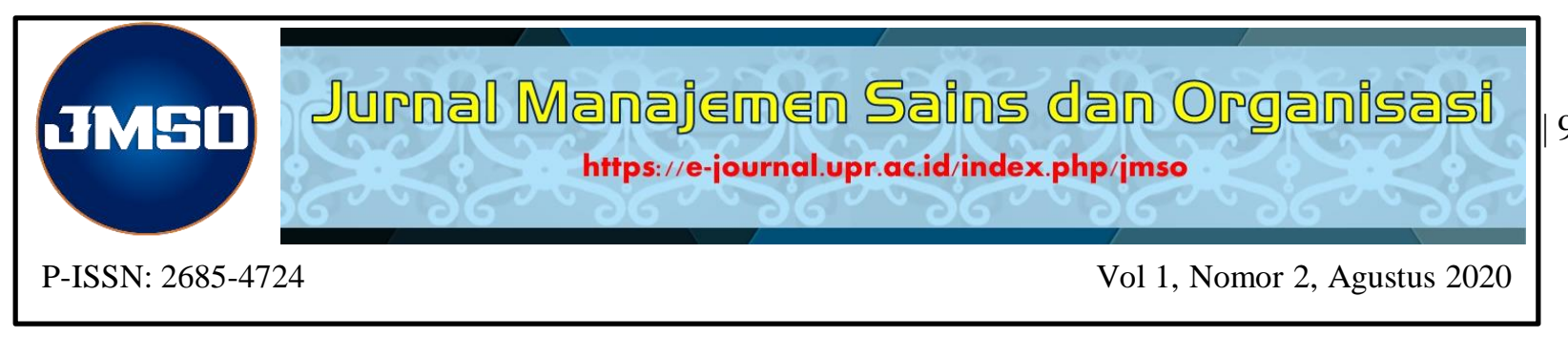

\title{
Pengaruh kompensasi finansial terhadap kinerja karyawan dengan disiplin kerja sebagai mediasi pada Perum Damri Palangka Raya
}

\author{
Wahyu Sigit Widodo ${ }^{1}$, \\ Fakultas Ekonomi dan Bisnis \\ Universitas Palangka Raya, Indonesia \\ Anike Retawati $^{2}$,
Fakultas Ekonomi dan Bisnis
Universitas Palangka Raya, Indonesia \\ Fiasco Darung ${ }^{3)}$ \\ Fakultas Ekonomi dan Bisnis \\ Universitas Palangka Raya, Indonesia \\ Email: wahyusigitwidodo2@gmail.com
}

\begin{abstract}
Abstrak
Tujuan - Penelitian ini bertujuan untuk memberikan penjelasan secara empiris tentang pengaruh kompensasi finansial terhadap kinerja karyawan dengan menggunakan disiplin kerja sebagai variabel mediasi.

Desain/Metodelogi/Pendekatan - Metode penelitian yang digunakan deskriptif-kuantitatif. Unit analisa penelitian ini adalah karyawan PERUM DAMRI Palangka Raya yang berjumlah 62 orang dengan teknik sampel sensus. Data yang terkumpul dianalisis menggunakan Structural Equetion Modelling (SEM) dengan bantuan Software SmartPLS 3.2.7.

Temuan - Hasil penelitan menunjukan bahwa kompensasi finansial berpengaruh terhadap disiplin kerja, kompensasi finansial berpengaruh terhadap kinerja karyawan, dan disiplin kerja sebagai mediator pengaruh antara kompensasi finansial terhadap kinerja karyawan
\end{abstract}

Kata kunci: Kompensasi Finansial, Disiplin Kerja, dan Kinerja Karyawan

\section{The effect of financial compensation on employee performance with work discipline as mediation at Perum Damri Palangka Raya}

Abstract

Purpose - This investigation expects to give an exact clarification of the impact of financial compensation on worker execution by utilizing work discipline as an intervening variable.

Design / Methodology / Approach - The examination strategy utilized is distinct quantitative. The unit of investigation in this exploration is the representatives of PERUM DAMRI Palangka Raya, adding up to 62 individuals with the enumeration test procedure. The gathered information were investigated utilizing Structural Equetion Modeling (SEM) with the assistance of SmartPLS 3.2.7 Software..

Findings - The aftereffects of the investigation show that financial compensation affects work discipline, monetary remuneration affects representative execution, and work discipline as a middle person for the impact of monetary pay on worker execution.

Keywords: Financial Compensation, Work Discipline, and Employee Performance

Wahyu Sigit Widodo , Anike Retawati, and Damus DJantra. Published in the Jurnal Manajemen sains dan Organsasi. Published by FEB UPR Publishing Limited. This article is published under the Creative Commons Attribution (CC BY 4.0) licence. Anyone may reproduce, distribute, translate and create derivative works of this article (for both commercial and non-commercial purposes), subject to full attribution to the original publication and authors. 


\section{PENDAHULUAN}

Peranan sumber daya manusia yang begitu penting dalam mengendalikan perusahaan atau organisasi, dapat dikatakan melebihi peranan sumber daya lainnya. Ketika perusahaan atau organisasi tidak dapat mengelola sumber daya manusia dengan tepat dan baik, maka sumber daya yang lain seperti uang, teknologi, alam tidak dapat dikelola secara optimal. Selain itu dalam suatu perusahaan atau organisasi juga perlu adanya upaya untuk memperbaiki kualitas karyawan agar memiliki kinerja yang baik dan mampu menghadapi persaingan.

Memperhatikan sangat pentingnya peranan sumber daya manusia ini maka perusahaan harus memanfaatkan SDM nya dengan seefisien dan seefektif mungkin agar karyawan memiliki disiplin kerja yang tinggi untuk menghasilakn kinerja yang baik. Salah satu untuk meningkatkan disiplin kerja melalui pemberian kompensasi finansial yang sesuai sebagai balas jasa kepada karyawan atas usaha yang mereka lakukan kepada perusahaan, hal ini dikarenakan setiap orang bekerja memiliki motif untuk mendapatkan keuntungan atau manfaaf dalam bekerja dan pada dasarnya akan meningkatkan kinerja karyawan dalam suatu perusahaan.

Disiplin kerja merupakan salah satu komponen yang turut menentukan baik buruknya kinerja seseorang. Karyawan yang disiplin dalam bekerja akan cenderung untuk melakukan segala aktivitasnya sesuai dengan tata aturan, standar maupun tugas dan tanggung jawab yang menjadi kewajibannya. Kepatuhan terhadap peraturan maupun standar kerja yang telah ditetapkan oleh manajemen merupakan jaminan keberhasilan pencapaian tujuan oleh individu dalam organisasi yang bersangkutan yang pada dasarnya akan mempengaruhi kinerja organisasi tersebut.

Perusahaan Umum Djawatan Angkoetan Motor Repoeblik Indonesia atau yang lebih dikenal dengan nama singkatannya sebagai PERUM DAMRI Palangka Raya, adalah salah satu perusahaan yang tugas utamanya menyelenggarakan jasa angkutan penumpang dan barang dengan menggunakan kendaraan bermotor. Adapun hasil observasi yang penulis lakukan di lokasi penelitian, fenomena mendasar yang penulis temukan yaitu Gaji pokok karyawan sesuai dengan surat keputusan (SK) berdasarkan Golongan dan sesuai Usia Masa Kerja (UMK) karyawan, adanya tunjangan-tunjangan seperti tunjangan hari raya sesuai UMK, tunjangan jabatan dan lain sebagainya, Masih terdapat karyawan yang melaksanakan tugasnya kurang baik, seperti masih adanya karyawan yang terlambat pada waktu yang telah ditetapkan atau pada jam kerja, Masih terdapat karyawan yang tidak pada posisinya dengan alasan yang tidak jelas, dan pulang kerja sebelum waktu yang ditentukan. Sehingga hal tersebut dapat mempengaruhi kinerja karyawan.

Pemberian kompensasi yang tepat akan berpengaruh positif terhadap karyawan, karena tidak dapat dipungkiri bahwa kompensasi menjadi tujuan utama untuk sebagian besar karyawan yang bekerja di dalam suatu perusahaan. Menurut Ardana (2012), segala sesuatu yang diterima oleh karyawan mengenai (urusan) keuangan sebagai balas jasa atas kontribusi kepada perusahaan atau organisasi dapat dikatakan sebagai kompensasi finansial. Bila kompensasi tidak dikelola dengan baik, akan mengganggu jalannya usaha. Sedangkan menurut Hasibuan (2012), kompensasi finansial adalah semua pendapatan yang berbentuk uang, langsung atau tidak langsung yang diterima karyawan sebagai imbalan balas jasa yang diberikan kepada perusahaan.

Setiap organisasi atau perusahaan memerlukan sumber daya manusia yang 
berkualitas, yang mempunyai kompetensi, dan siap untuk bersaing di dunia bisnis. Untuk memenuhi kebutuhan tersebut, setiap organisasi harus bisa mengarahkan para karyawannya untuk disiplin di dalam bekerja. Runik Puji Rahayu (2006) dalam penelitiannya, dari hasil perhitungan dari kedua variabel bebas kompensasi finansial $\left(\mathrm{X}_{1}\right)$, kompensasi non finansial $\left(\mathrm{X}_{2}\right)$ memberikan pengaruh paling dominan terhadap Disiplin Kerja (Y) adalah variabel kompensasi finansial $\left(\mathrm{X}_{1}\right)$.

H1: Kompensasi finansial berpengaruh terhadap disiplin kerja karyawan PERUM DAMRI Palangka Raya.

Disiplin kerja sangat berpengaruh terhadap hasil kerja dimana ketika seseorang karyawan mampu mematuhi peraturan yang ditetapkan sebuah organisasi , karyawan akan menghasilkan kinerja yang baik. Menurut Mangkunegara (2013), kinerja karyawan adalah hasil kerja secara kualitas dan kuantitas yang dicapai oleh seorang pegawai dalam melaksanakan tugasnya sesuai dengan tanggung jawab yang diberikan. Sedangkan menurut Bangun (2012), kinerja karyawan adalah hasil pekerjaan yang dicapai karyawan berdasarkan persyaratan-persyaratan pekerjaan. Karyawan adalah orang yang melakukan pekerjaan dengan mendapatkan imbalan jasa berupa gaji dan tunjangan dari organisasi atau perusahaan. Listya Maretha Sari (2010) dalam penelitiannya menunjukan bahwa secara parsial variabel kompensasi finansial yang terdiri dari kompensasi finansial langsung dan kompensasi finansial tidak langsung berpengaruh terhadap kinerja karyawan.

H2: Kompensasi finansial berpengaruh terhadap kinerja karyawan PERUM DAMRI Palangka Raya.

Menurut Sutrisno (2013) dalam arti yang lebih sempit dan lebih banyak dipakai, disiplin berarti tindakan yang diambil untuk mengoreksi perilaku dan sikap yang salah pada karyawan. Sedangkan menurut Mangkunegara dalam Sinambela (2012), disiplin kerja merupakan ukuran aktivitas organisasi untuk memanfaatkan semua sumbangan atau kemampuan yang ada secara optimal untuk mencapai tujuan, dengan menaati segala peraturan yang telah ditetapkan. Muhammad Taufik Rio Sanjaya (2014) dalam penelitianya, disiplin kerja $\left(\mathrm{X}_{1}\right)$ berpengaruh positif sebesar 0,624 atau $62,4 \%$ dan motivasi kerja $\left(\mathrm{X}_{2}\right)$ berpengaruh positif 0,788 atau $78,8 \%$ terhadap kinerja karyawan Hotel Ros In Yogyakarta pada tingkat kepercayaan 95\%.

H3: Disiplin kerja berpengaruh terhadap kinerja karyawan PERUM DAMRI Palangka Raya.

H4: Kompensasi finansial berpengaruh terhadap kinerja karyawan melalui disiplin kerja sebagai variabel mediator 


\section{Gambar 1: Kerangka konseptual penelitian}

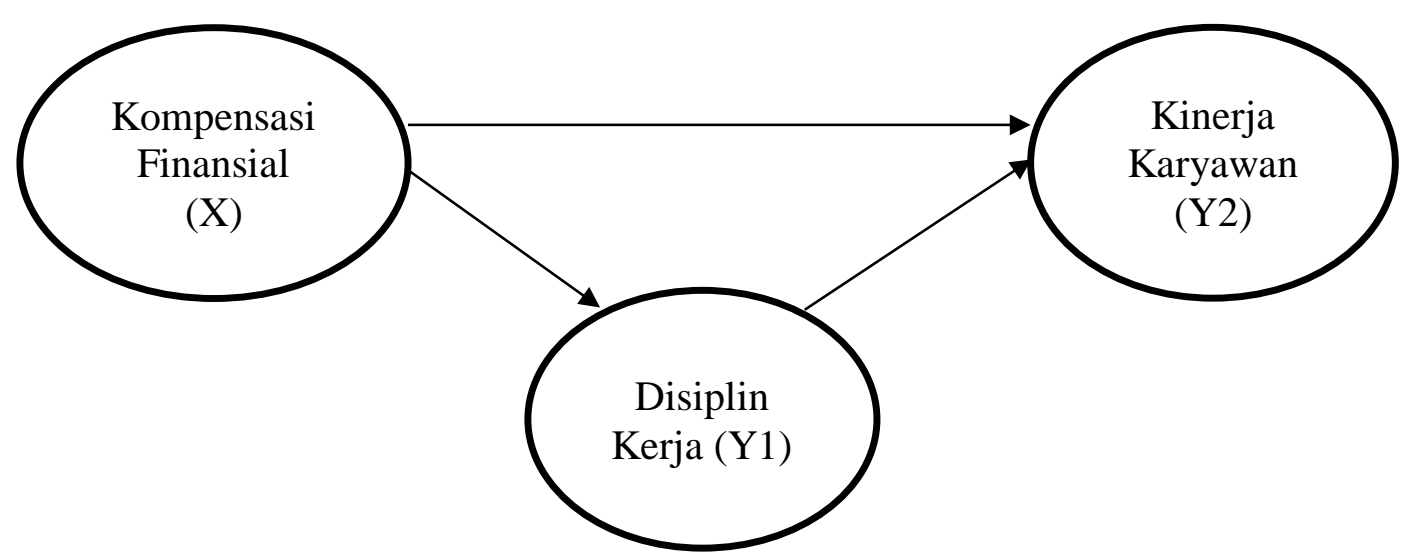

Desain penelitian yang digunakan dalam penelitian ini adalah deskriptif dengan pendekatan kuantitatif. Sumber data diperoleh dari penyebaran kusioner pada karyawan PERUM DAMRI Palangka Raya yang berjumlah 62 responden sebagai sampel penelitian dengan teknik sampel jenuh (sensus).

Variabel dan indikator yang digunakan dalam penelitian ini dapat dilihat dalam tabel berikut ini:

Tabel 1: Identifikasi Variabel

\begin{tabular}{|c|c|c|}
\hline Variabel & Definisi & Indikator \\
\hline $\begin{array}{ll}\text { Kompensasi } & \text { Finansial } \\
\text { (X1) } & \end{array}$ & $\begin{array}{l}\text { Kompensasi finansial adalah sesuatu } \\
\text { yang diterima karyawan yang berbentuk } \\
\text { uang (mengenai keuangan) atas jasa yang } \\
\text { mereka sumbangkan pada pekerjaannya } \\
\text { (Bangun, 2012). }\end{array}$ & $\begin{array}{ll}\text { 1. } & \text { Gaji } \\
\text { 2. } & \text { Upah } \\
\text { 3. } & \text { Insentif } \\
\text { 4. } & \text { Bonus } \\
\text { 5. } & \text { Tunjangan-tunjangan } \\
\text { 6. } & \text { Jaminan sosial } \\
\text { 7. } & \text { Asuransi } \\
\text { 8. } & \text { Uang cuti } \\
\text { 9. } & \text { Liburan } \\
\text { 10. } & \text { Uang pensiun }\end{array}$ \\
\hline Disiplin Kerja (Y1) & $\begin{array}{l}\text { Menurut Mangkunegara dalam } \\
\text { Sinambela (2012), disiplin kerja } \\
\text { merupakan ukuran aktivitas organisasi } \\
\text { untuk memanfaatkan semua sumbangan } \\
\text { atau kemampuan yang ada secara optimal } \\
\text { untuk mencapai tujuan, dengan menaati } \\
\text { segala peraturan yang telah ditetapkan. }\end{array}$ & $\begin{array}{l}\text { 1. Selalu hadir tepat waktu } \\
\text { 2. Selalu mengutamakan } \\
\text { persentase kehadiran } \\
\text { 3. Selalu mentaati jam kerja } \\
\text { 4. Memiliki semangat kerja } \\
\text { yang tinggi } \\
\text { 5. Memiliki sikap yang baik }\end{array}$ \\
\hline Kinerja Karyawan (Y2) & $\begin{array}{l}\text { Menurut Bangun (2012) kinerja } \\
\text { karyawan adalah hasil pekerjaan yang } \\
\text { dicapai karyawan berdasarkan } \\
\text { persyaratan-persyaratan pekerjaan }\end{array}$ & $\begin{array}{ll}\text { 1. } & \text { Jumlah pekerjaan } \\
\text { 2. } & \text { Kualitas pekerjaan } \\
\text { 3. } & \text { Ketepatan waktu } \\
\text { 4. Kehadiran } \\
\text { 5. Kemampuan kerja sama }\end{array}$ \\
\hline
\end{tabular}

Data dianalisis dengan menggunakan SmartPLS (Partial Least Square). PLS adalah salah 
satu metode alternatif SEM (Structural Equation Modeling) yang digunakan untuk mengatasi permasalahan dalam hubungan.

\section{HASIL DAN PEMBAHASAN}

Setelah pengumpulan data dengan mengunakan kuesioner yang disebarkan kepada responden yakni seluruh karyawan PERUM DAMRI Palangka Raya yang berjumlah 62 orang. Informasi tentang karakteristik responden dapat dilihat pada Tabel 2. berikut ini.

Tabel 2: Karakteristik Responden

\begin{tabular}{lcc}
\hline \multicolumn{1}{c}{ Karakteristik } & Frekuensi & $\mathbf{\%}$ \\
Laki-Laki & 56 & $90 \%$ \\
Perempuan & 6 & $10 \%$ \\
Total & $\mathbf{6 2}$ & $\mathbf{1 0 0 \%}$ \\
$<20$ tahun & 1 & $1,61 \%$ \\
20 - 30 tahun & 23 & $37,10 \%$ \\
$31-40$ tahun & 25 & $40,32 \%$ \\
$41-50$ tahun & 10 & $16,13 \%$ \\
$>$ 50 tahun & 3 & $4,84 \%$ \\
Total & $\mathbf{6 2}$ & $\mathbf{1 0 0 \%}$ \\
& & \\
\hline SD & 2 & $3 \%$ \\
SMP & 13 & $21 \%$ \\
SMA & 43 & $69 \%$ \\
S1 & 4 & $\mathbf{1 0 0 \%}$ \\
Total & $\mathbf{6 2}$ & \\
\hline
\end{tabular}

Sumber: Data Primer, 2019

Tabel 2 menunjukkan bahwa responden yang berjenis kelamin Laki-Laki sebanyak 56 orang $(90 \%)$ dan Perempuan sebanyak 6 orang $(10 \%)$. Jumlah responden yang berusia < 20 tahun sebanyak 1 orang $(1,61 \%)$, usia $20-30$ tahun sebanyak 23 orang $(37,10 \%)$, usia $31-40$ sebanyak 25 orang $(40,32 \%)$, usia $41-50$ tahun sebanyak 10 orang $(16,13 \%)$ dan usia $>50$ tahun sebanyak 3 orang $(4,48 \%)$. Karakteristik responden berdasarkan jenjang pendidikan SD/sedrajat sebanyak 2 orang (3\%), SMP sebanyak 13 orang (21\%), SMA sebanyak 43 orang (69\%), S1 sebanyak 4 orang $(6 \%)$.

\section{Evaluasi Measurement model (Outer model)}

Adapun model pengukuran untuk uji validitas dan reliabilitas, koefisien determinasi model dan koefisien jalur, dapat dilihat pada Gambar 2 berikut: 
Gambar 2: Tampilan Hasil PLS Algorithm

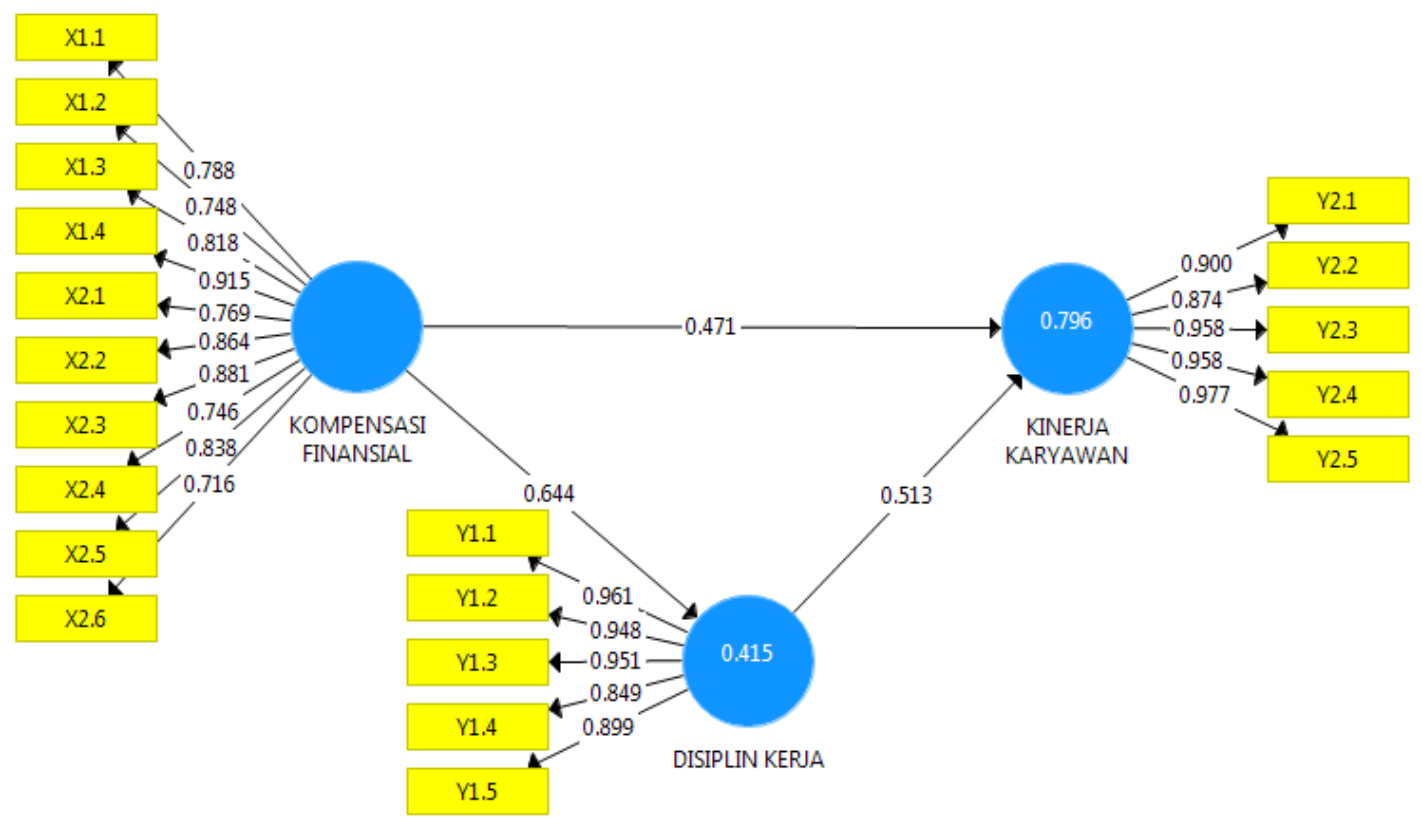

Sumber: Hasil Perhitungan Akhir Algorithm PLS

Sedangkan untuk rangkuman hasil uji validitas dan hasil uji reliabilitas dapat dilihat pada Tabel 3 dan Tabel 4 sebagai berikut:

Tabel 3: Hasil Uji Validitas

\begin{tabular}{|c|c|c|c|c|}
\hline $\begin{array}{c}\text { Measurement } \\
\text { Model }\end{array}$ & Hasil & & $\begin{array}{c}\text { Nilai } \\
\text { Kritis }\end{array}$ & $\begin{array}{c}\text { Evaluasi } \\
\text { Model }\end{array}$ \\
\hline \multicolumn{5}{|c|}{ Outer Model } \\
\hline \multirow{4}{*}{$\begin{array}{l}\text { Discriminant } \\
\text { Validity }\end{array}$} & Variabel & $A V E$ & \multirow{4}{*}{$>0,5$} & \\
\hline & Kompensasi Finansial & 0,851 & & Valid \\
\hline & Disiplin Kerja & 0,873 & & Valid \\
\hline & Kinerja Karyawan & 0,657 & & Valid \\
\hline $\begin{array}{l}\text { Convergen } \\
\text { Validity }\end{array}$ & Indikator & $\begin{array}{c}\text { Cross } \\
\text { Loading }\end{array}$ & & \\
\hline & $\mathrm{X} 1.1$ & 0,788 & \multirow{14}{*}{$>0,7$} & Valid \\
\hline & $\mathrm{X} 1.2$ & 0,748 & & Valid \\
\hline & $\mathrm{X} 1.3$ & 0,818 & & Valid \\
\hline & $\mathrm{X} 1.4$ & 0,915 & & Valid \\
\hline & $\mathrm{X} 1.5$ & 0,769 & & Valid \\
\hline & $\mathrm{X} 1.6$ & 0,864 & & Valid \\
\hline & $\mathrm{X} 1.7$ & 0,881 & & Valid \\
\hline & $\mathrm{X} 1.8$ & 0,746 & & Valid \\
\hline & $\mathrm{X} 1.9$ & 0,838 & & Valid \\
\hline & $\mathrm{X} 1.10$ & 0,716 & & Valid \\
\hline & Y1.1 & 0,961 & & Valid \\
\hline & $\mathrm{Y} 1.2$ & 0,948 & & Valid \\
\hline & Y1.3 & 0,951 & & Valid \\
\hline & Y1.4 & 0,849 & & Valid \\
\hline
\end{tabular}




\begin{tabular}{ccccc}
\hline $\begin{array}{c}\text { Measurement } \begin{array}{c}\text { Model } \\
\text { Monn }\end{array} \\
\text { Y1.5 }\end{array}$ & Hasil & & $\begin{array}{c}\text { Nilai } \\
\text { Kritis }\end{array}$ & $\begin{array}{c}\text { Evaluasi } \\
\text { Model }\end{array}$ \\
\hline Y2.1 & & & Valid \\
\hline Y2.2 & 0,899 & & Valid \\
\hline Y2.3 & 0,900 & & Valid \\
\hline Y2.4 & 0,874 & 0,958 & & Valid \\
\hline Y2.5 & 0,958 & & Valid \\
\hline
\end{tabular}

Sumber: Data primer diolah, 2019

Berdasarkan Tabel 3. nilai $A V E$ variabel kompensasi finansial (X), disiplin kerja (Y1) dan kinerja karyawan (Y2) diatas 0,5. Dengan demikian dapat dinyatakan bahwa setiap variabel telah memiliki discriminant validity yang baik. Sedangkan untuk convergen validity, diketahui bahwa masing-masingindikator variabel penelitian memiliki nilai outer loading diatas 0,7 sehingga semua indikator dinyatakan valid atau layak untuk digunakan untuk penelitian dan analisis lebih lanjut.

Tabel 4: Hasil Uji Reliabilitas

\begin{tabular}{|c|c|c|c|c|c|}
\hline Variabel & $\begin{array}{l}\text { Composite } \\
\text { Reliability }\end{array}$ & $\begin{array}{l}\text { Nilai } \\
\text { Kritis }\end{array}$ & $\begin{array}{c}\text { Cronbach's } \\
\text { Alpha }\end{array}$ & $\begin{array}{l}\text { Nilai } \\
\text { Kritis }\end{array}$ & $\begin{array}{c}\text { Evaluasi } \\
\text { Model }\end{array}$ \\
\hline $\begin{array}{l}\text { Kompensasi } \\
\text { Finansial }\end{array}$ & 0,966 & \multirow{3}{*}{$>0,7$} & 0,956 & \multirow{3}{*}{$>0,6$} & \multirow{3}{*}{ Reliabel } \\
\hline Disiplin Kerja & 0,972 & & 0,963 & & \\
\hline Kinerja Karyawan & 0,950 & & 0,741 & & \\
\hline
\end{tabular}

Sumber: Data primer diolah, 2019

Konstruk dinyatakan reliabel jika memiliki nilai composite reliability di atas 0,7 dan cronbach's alpha di atas 0,6. Berdasarkan Tabel 4, semua konstruk memiliki nilai composite reliability di atas 0,7 dan cronbach's alpha di atas 0,6. Jadi dapat disimpulkan bahwa konstruk memiliki reliabilitas yang baik.

\section{Pengujian Inner Model (Model Struktural)}

Pengujian inner model dilakukan untuk melihat nilai signifikasi hubungan antara variabel laten dengan uji t sesuai parameter jalur strukturalnya dan nilai $\mathrm{R}$-square dari model penelitian. Pengujian tersebut dilakukan melalui SmartPLS 3.2.7 dengan melakukan langkah calculate-boostrapping dan diperoleh hasil sebagai berikut:

Tabel 5. Path Coefficient (Mean, STDEV, T-Value, P-Values)

\begin{tabular}{ccccccc}
\hline & $\begin{array}{c}\text { Original } \\
\text { Sample }\end{array}$ & $\begin{array}{c}\text { Samples } \\
\text { Mean }\end{array}$ & $\begin{array}{c}\text { Standard } \\
\text { Deviation }\end{array}$ & $\begin{array}{c}\boldsymbol{t} \text { - } \\
\text { statistic }\end{array}$ & $\begin{array}{c}\boldsymbol{p} \\
\text { values }\end{array}$ & Keterangan \\
\hline $\mathrm{Y1} \rightarrow \mathrm{Y2}$ & 0,513 & 0,508 & 0,166 & 3,092 & 0,002 & Signifikan \\
& & & & & & \\
\hline $\mathrm{X} \rightarrow \mathrm{Y1}$ & 0,644 & 0,644 & 0,115 & 5,582 & 0,000 & Signifikan \\
\hline $\mathrm{X} \rightarrow \mathrm{Y2}$ & 0,471 & 0,478 & 0,158 & 2,987 & 0,003 & Signifikan \\
\hline
\end{tabular}

Sumber: Data primer diolah, 2019 
Tabel 6: Specific Indirect Effects (Mean, STDEV, T-Value, P-Values)

\begin{tabular}{ccccccc}
\hline & $\begin{array}{c}\text { Original } \\
\text { Sample }\end{array}$ & $\begin{array}{c}\text { Samples } \\
\text { Mean }\end{array}$ & $\begin{array}{c}\text { Standard } \\
\text { Deviation }\end{array}$ & $\begin{array}{c}t \text { - } \\
\text { statistic }\end{array}$ & $\begin{array}{c}p \\
\text { values }\end{array}$ & Keterangan \\
\hline $\mathrm{X} \rightarrow \mathrm{Y1} \rightarrow \mathrm{Y2}$ & 0,330 & 0,349 & 0,126 & 2,630 & 0,009 & Signifikan \\
\hline
\end{tabular}

Sumber: Data primer diolah, 2019

Tabel 7: Total Effects (Mean, STDEV, T-Value, P-Values)

\begin{tabular}{ccccccc}
\hline & $\begin{array}{c}\text { Original } \\
\text { Sample }\end{array}$ & $\begin{array}{c}\text { Samples } \\
\text { Mean }\end{array}$ & $\begin{array}{c}\text { Standard } \\
\text { Deviation }\end{array}$ & $\begin{array}{c}\boldsymbol{t} \text { - } \\
\text { statistic }\end{array}$ & $\boldsymbol{p}$ values & Keterangan \\
\hline $\mathbf{Y I ~} \rightarrow \mathbf{Y 2}$ & 0,513 & 0,543 & 0,169 & 3,028 & 0,003 & Signifikan \\
& & & & & & \\
\hline $\mathbf{X} \rightarrow \mathbf{Y 1}$ & 0,644 & 0,645 & 0,109 & 5,882 & 0,000 & Signifikan \\
\hline $\mathbf{X} \rightarrow \mathbf{Y 2}$ & 0,801 & 0,795 & 0,075 & 10,642 & 0,000 & Signifikan \\
\hline
\end{tabular}

Sumber: Data primer diolah, 2019

Pengujian pertama dilakukan untuk melihat apakah kompensasi finansial berpengaruh positif terhadap disiplin kerja. Hasil pengujian Tabel 5, X $\rightarrow$ Y1 memperoleh nilai original sample estimate sebesar 0,644 dengan nilai t-statistik 5,582 > 2,001 serta p-values $0,000<0,05$ yang berarti kompensasi finansial berpengaruh positif terhadap disiplin kerja. Berdasarkan hasil pengujian tersebut dapat disimpulkan bahwa hipotesis H1 diterima.Penelitian ini sejalan dengan penelitian yang dilakukan oleh Runik Puji Rahayu (2006) yang menyatakan bahwa kompensasi finansial berpengaruh terhadap disiplin kerja

Pengujian kedua dilakukan untuk melihat apakah kompensasi finansial berpengaruh positif terhadap kinerja karyawan. Hasil pengujian dari Tabel 5, nilai original sample estimate X -> Y2 adalah sebesar 0,471 dengan signifikan yang di tunjukkan dengan nilai t-statistik 2,987 lebih besar dari nilai t-tabel sebesar 2,001 serta p-values 0,003 lebih kecil dari 0,05. Kemudian pada pengaruh langsung kompensasi finansial terhadap kinerja karyawan dengan koefisien jalur 0,471 sedangkan untuk pengaruh tidak langsung sebesar 0,330 . Untuk melihat pengaruh totalnya pengaruh langsung ditambah pengaruh tidak langsung $(0,471+0,330=0,801)$. Hasil ini memperkuat bahwa pengaruh kompensasi finansial terhadap kinerja karyawan positif. Berdasarkan hasil tersebut dapat disimpulkan bahwa hipotesis $\mathrm{H} 2$ diterima. Penelitian ini sejalan dengan penelitian yang dilakukan oleh Listya Maretha Sari (2010) yang menyatakan bahwa kompensasi finansial berpengaruh terhadap kinerja karyawan.

Pengujian ketiga dilakukan untuk melihat apakah disiplin kerja berpengaruh terhadap kinerja karyawan. Hasil pengujian dapat Tabel 5, Y1 -> Y2 memperoleh nilai original sample estimate sebesar 0,513 dengan nilai t-statistik 3,092 > 2,001 serta pvalues $0,002<0,05$ yang berarti disiplin kerja berpengaruh positif terhadap kinerja karyawan. Berdasarkan hasil pengujian tersebut dapat disimpulkan bahwa hipotesis $\mathrm{H} 3$ diterima. Penelitian ini sejalan dengan penelitian yang dilakukan oleh Riga Putra Kurniawan (2012) yang menyatakan bahwa disiplin kerja berpengaruh signifikan terhadap kinerja karyawan. 
Ghozali (2015) menjelaskan bahwa model untuk menguji efek mediasi dengan cara menguji secara simultan pengaruh variabel eksogen $(\mathrm{X})$ dan mediasi (Y1) terhadap variabel endogen (Y2). Pada pengujian tahap akhir diharapkan berpengaruh signifikan pada T-statistik > 2,001. Dari penjelasan tersebut pada Tabel 7, Total Effects X -> Y2 nilai t-statistik sebesar 10,642 lebih besar dari nilai t-table 2,001. Sesuai dengan yang diharapkan pada pengujian tahap akhir. Sedangkan untuk pengaruh variabel disiplin kerja (Y1) terhadap kinerja karyawan (Y2) pada Tabel 7 nilai t-statistik sebesar 3,028 lebih besar dari nilai t-tabel 2,001 sesuai dengan penjelasan Ghozali tentang model pengujian efek mediasi. Kemudian pada Tabel 6, dapat dilihat Specific Indirect Effects dari X -> Y1 -> Y2, nilai original sample estimate sebesar 0,330 dan nilai t-statistik sebesar 2,630 di atas nilai t-tabel 2,001 serta p-values $0,009<0,05$ yang berarti kompensasi finansial berpengaruh positif dan signifikan terhadap kinerja karyawan melalui disiplin kerja, dengan pengaruh mediasi sempurna (full mediation). Berdasarkan hasil hasil pengujian tersebut dapat disimpulkan bahwa hipotesis $\mathrm{H} 4$ diterima.

\section{R-Square}

Tabel 8: R- Square

\begin{tabular}{lc}
\hline \multicolumn{1}{c}{ Endogen Variabel } & Nilai R-Square \\
\hline Disiplin Kerja (Y1) & 0.415 \\
\hline Kinerja Karyawan (Y2) & 0.796 \\
\hline
\end{tabular}

Sumber: Pengolahan data dengan SmartPLS, 2019

Pada Tabel 8, dapat diketahui nilai R-square untuk disiplin kerjasebesar 0,415 yang berarti variabel kompensasi finansial mempengaruhi variabel disiplin kerja.

Sedangkan untuk variabel kinerja karyawan nilai R-square sebesar 0,796 yang artinya variabel kompensasi finansial mempengaruhi variabel kinerja karyawan melalui variabel disiplin kerja.

Tabel 9: Uji koefisien jalur antar variabel

\begin{tabular}{lcccc}
\hline $\begin{array}{c}\text { Variabel } \\
\text { Independen }\end{array}$ & $\begin{array}{c}\text { Variabel } \\
\text { Dependen }\end{array}$ & Pengaruh Langsung & $\begin{array}{c}\text { Pengaruh } \\
\text { Tidak } \\
\text { Langsung }\end{array}$ & $\begin{array}{c}\text { Pengaruh } \\
\text { Total }\end{array}$ \\
\hline Kompensasi Finansial & $\begin{array}{c}\text { Disiplin } \\
\text { Kerja }\end{array}$ & 0,644 & 0,330 & 0,801 \\
\hline Kompensasi Finansial & $\begin{array}{c}\text { Kinerja } \\
\text { Karyawan }\end{array}$ & $\mathbf{0 , 4 7 1}$ & & \\
\hline Disiplin Kerja & $\begin{array}{c}\text { Kinerja } \\
\text { Karyawan }\end{array}$ & $\mathbf{0 , 5 1 3}$ & & \\
\hline
\end{tabular}

Sumber: Data primer diolah, 2019

Pada Tabel 8, dapat dijelaskan bahwa nilai path coefficient terbesar ditunjukkan dengan pengaruh kompensasi finansial terhadap disiplin kerja sebesar 0,644. kemudian pengaruh terbesar kedua adalah pengaruh disiplin kerja terhadap kinerja karyawan sebesar 0,513 dan pengaruh yang paling kecil ditunjukan oleh pengaruh kompensasi finansial terhadap kinerja karyawan sebesar 0,471. 


\section{SIMPULAN}

Penelitian ini memberikan bukti empiris mengenai pengaruh kompensasi finansial terhadap kinerja karyawan melalui disiplin kerja sebagai mediator. Hasil penelitiani ini disimpulkan bahwa kompensasi finansial berpengaruh terhadap disiplin kerja karyawan PERUM DAMRI Palangka Raya, sehingga hipotesis pertama dapat diterima dan teruji kebenarannya. Kompensasi finansial berpengaruh terhadap kinerja karyawan PERUM DAMRI Palangka Raya, sehingga hipotesis kedua dapat diterima dan teruji kebenarannya. Disiplin kerja berpengaruh terhadap kinerja karyawan PERUM DAMRI Palangka Raya, sehingga hipotesis ketiga dapat diterima dan teruji kebenarannya.Kompensasi finansial berpengaruh terhadap kinerja karyawan melalui disiplin kerja pada karyawan PERUM DAMRI Palangka Raya, sehingga hipotesis keempat dapat diterima dan teruji kebenarannya.

Berdasarkan kesimpulan tersebut maka disaran untuk penelitian selanjutnya diharapkan agar mendapatkan suatu model penelitian yang baik dengan didukung oleh teori yang kuat dan disarankan untuk lebih memperbanyak referensi penelitian yang mampu mendukung topik yang diteliti.

\section{REFERENSI}

Ardana Komang. 2012. Manajemen Sumber Daya Manusia. Yogyakarta; Graha Ilmu

Bangun, Wilson. 2012. Manajemen Sumber Daya Manusia. Jakarta; Erlangga

Darsono dan Tjatjuk, Siswandoko. 2011. Manajemen Sumber Daya Manusia $\quad$ Abad 21. Jakarta; Nusantara Consulting

Ghozali, Imam. 2014. Structural Equetion Modeling, Metode Alternative dengan

Partial Least Square (PLS). Edisi 4. Semarang; Universitas Diponegoro

Hasibuan, SP, Malayu. 2012. Manajemen Sumber Daya Manusia Edisi Revisi,

Cetakan Keenam Belas. Jakarta; PT. Bumi Aksara

Mangkunegara, A. A Anwar, Prabu. 2013. Manajemen Sumber Daya Manusia

Perusahaan. Bandung; PT. Remaja Rosdakarya

Sinambela, dkk. 2012. Kinerja Pegawai Teori Pengukuran dan Implikasi. Yogyakarta; Graha Ilmu

Sutrisno, Edy, 2013. Manajemen Sumber Daya Manusia. Yogyakarta; Graha Ilmu 